\title{
Aceclofenac nanocrystals with enhanced in vitro, in vivo performance: formulation optimization, characterization, analgesic and acute toxicity studies
}

\author{
This article was published in the following Dove Press journal: \\ Drug Design, Development and Therapy \\ 23 August 2017 \\ Number of times this article has been viewed
}

\author{
Haroon Rahim' \\ Abdul Sadiq' \\ Shahzeb Khan' \\ Mir Azam Khan' \\ Syed Muhammad Hassan \\ Shah $^{2}$ \\ Zahid Hussain ${ }^{3}$ \\ Riaz Ullah ${ }^{4}$ \\ Abdelaaty Abdelaziz \\ Shahat ${ }^{4,5}$ \\ Khalid Ibrahim ${ }^{6}$ \\ 'Department of Pharmacy, University \\ of Malakand, Chakdara, ${ }^{2}$ Department \\ of Pharmacy, Sarhad University of \\ Science and Information Technology \\ Peshawar, Khyber Pakhtunkhwa, \\ Pakistan; ${ }^{3}$ Faculty of Pharmacy, \\ Department of Pharmaceutics, \\ Universiti Teknologi, Mara, \\ Selangor, Malaysia; ${ }^{4}$ Department \\ of Pharmacognosy and Medicinal, \\ Aromatic and Poisonous Plants \\ Research Center, College of Pharmacy, \\ King Saud University, Riyadh, Saudi \\ Arabia; ${ }^{5}$ Phytochemistry Department, \\ National Research Center, Dokki, \\ Giza, Egypt; ${ }^{6}$ Department of Chemical \\ Engineering, College of Engineering, \\ Al-Muzahmeiah Branch, King Saud \\ University, Riyadh, Saudi Arabia
}

Correspondence: Shahzeb Khan; Abdul Sadiq

Department of Pharmacy, University of Malakand, Dir (Lower), Chakdara 23050, KPK, Pakistan

Tel +92 345949 2869;

+923325046485

Email shahzeb333@hotmail.com; sadiquom@yahoo.com
Abstract: This study was aimed to enhance the dissolution rate, oral bioavailability and analgesic potential of the aceclofenac (AC) in the form of nanosuspension using cost-effective simple precipitation-ultrasonication approach. The nanocrystals were produced using the optimum conditions investigated for AC. The minimum particle size (PS) and polydispersity index was found to be $112 \pm 2.01 \mathrm{~nm}$ and 0.165 , respectively, using hydroxypropyl methylcellulose $(1 \%$, w/w), polyvinylpyrrolidone $\mathrm{K} 30(1 \%, \mathrm{w} / \mathrm{w})$ and sodium lauryl sulfate $(0.12 \%, \mathrm{w} / \mathrm{w})$. The characterization of AC was performed using zeta sizer, scanning electron microscopy, transmission electron microscopy, powder X-ray diffraction and differential scanning calorimetry. The saturation solubility of the AC nanocrystals was substantially increased 2.6- and 4.5-fold compared to its unprocessed active pharmaceutical ingredient in stabilizer solution and unprocessed drug. Similarly, the dissolution rate of the AC nanocrystals was substantially enhanced compared to its other counterpart. The results showed that $>88 \%$ of AC nanocrystals were dissolved in first 10 min compared to unprocessed AC $(8.38 \%)$, microsuspension $(66.65 \%)$ and its marketed tablets (17.65\%). The in vivo studies of the produced stabilized nanosuspension demonstrated that the $\mathrm{C}_{\max }$ were 4.98- and 2.80-fold while area under curve from time of administration to $24 \mathrm{~h}\left(\mathrm{AUC}_{0 \rightarrow 24 \mathrm{~h}}\right)$ were found 3.88- and 2.10-fold greater when compared with unprocessed drug and its marketed formulation, respectively. The improved antinociceptive activity of AC nanocrystals was shown at much lower doses as compared to unprocessed drug, which is purely because of nanonization which may be attributed to improved solubility and dissolution rate of $\mathrm{AC}$, ultimately resulting in its faster rate of absorption.

Keywords: aceclofenac nanocrystals, precipitation-ultrasonication, dissolution rate, in vivo studies

\section{Introduction}

Poor water solubility and bioavailability are the major issues in the development of many active pharmaceutical ingredients (APIs). ${ }^{1}$ Micronization is not adequate to increase the surface area and consequently the drug dissolution rate for many poorly soluble drugs. The specific surface area of particles is highly increased and causes enhanced dissolution rate, if the size of the particles is altered from micron size to nanosize range. ${ }^{2,3}$ The bioavailability of these APIs can be enhanced by fabricating in the form of nanocrystals. ${ }^{4,5}$ The nanocrystals can be fabricated either by top-down or bottom-up approach. ${ }^{6-8}$ The former one requires expensive equipment as well as high energy inputs. In the last decade, bottom-up methods have been extensively considered to attain drug particles in nanosized range. ${ }^{9,10}$ To prepare either nano- or 
<smiles>O=C(O)COC(=O)Cc1ccccc1Nc1c(Cl)cccc1Cl</smiles>

Figure I Chemical structure of AC. Abbreviation: AC, aceclofenac.

micro-size particles of drug, the anti-solvent precipitation is an effective technique. In this method, the drug is dissolved in the solvent, followed by introducing into anti-solvent which results in the precipitation of drug. ${ }^{11}$ The major problems associated with anti-solvent precipitation technique include maintaining particle size (PS), stabilization after precipitation and scale up of the batch size. In the past decade, ultrasonication combined with precipitation has received great attention for controlling the nucleation and crystallization processes because of an efficient mass transfer to accelerate molecular diffusion. ${ }^{11-14}$ In order to achieve stability a range of stabilizers in use which includes hydroxypropyl methylcellulose (HPMC), polyvinylpyrrolidone (PVP), polyvinyl alcohol, etc. ${ }^{15,16}$

Aceclofenac (AC) is a well-known nonsteroidal antiinflammatory, analgesic drug (Figure 1). ${ }^{17}$ However, the therapeutic response of AC has been greatly affected by its poor water solubility, high permeability, and grouped into Biopharmaceutics Classification System class II drugs. ${ }^{18}$ Therefore, it would be imperative to produce stable AC-nanocrystals (AC-N) to address the problem of poor aqueous solubility and subsequently enhanced the bioavailability. Therefore, stable nanocrystals of AC were produced by using cost-effective simple precipitation combined with high energy inputs ultrasonication approach "Precipitation-Ultrasonication" with the aim to enhance the solubility, dissolution and hence the bioavailability of this important API.

\section{Materials and methods Materials}

AC (batch no 4021014154) and sodium lauryl sulfate (SLS) were a generous gift from Navegal Laboratories Hattar, Haripur, Khyber Pakhtunkhwa, Pakistan. Hydroxypropyl methylcellulose (HPMC 6cps), PVP K30 and ethanol were purchased from Peshawar, Pakistan.

All animal experiments were approved by the Ethical Committee of the University of Malakand and were conducted in accordance with their protocols and the relevant Bye-Laws 2008 (Scientific Procedure Issue-I).

\section{Preparation of AC-N}

$\mathrm{AC}$ was fabricated in the form of nanosuspension using "precipitation-ultrasonication approach". Briefly, AC $(30 \mathrm{mg} / \mathrm{mL})$ was dissolved in ethanol on basis of its solubility and was injected to antisolvent (pre-cooled at $4^{\circ} \mathrm{C}$ ) containing PVP K30 (1\%,w/w), HPMC (1\%,w/w) and SLS $(0.12 \%, w / w)$ solution prepared in aqueous medium at 1,500 rpm using magnetic stirrer. Afterward, ultrasonication of the produced suspension was carried for a different length of time $(10,15,20,25$ and $30 \mathrm{~min})$ at different ultrasonic inputs $(200,300$ and $400 \mathrm{~W})$ at a pause of $3 \mathrm{~s}$. The initial size of the AC-N was measured using Zetasizer (Nano-ZS instrument). ${ }^{19}$ After optimization of process and conditions for fabrication of AC-N, the batch size was successfully scaled up from $5 \mathrm{~mL}$ to $10,50,100,200,300$ and $400 \mathrm{~mL}$.

\section{Characterization of AC-N}

\section{PS and zeta potential measurement}

Malvern Zetasizer Nano-ZS dynamic light scattering instrument (Malvern Instruments, Malvern, UK), the PS and zeta potential were determined for $\mathrm{AC}-\mathrm{N}$ in the form of nanosuspensions. ${ }^{20}$

\section{Determination of active content of $A C$}

The nanosuspension were evaluated for AC active contents using reported HPLC method of Mutalik et al. ${ }^{17}$ High performance liquid chromatography system (LC-10ATVP Shimadzu, Kyoto, Japan) equipped with a UV-visible detector (SPD-10AV Shimadzu). Chromatographic conditions used as following: 1) mobile phase - methanol: $0.3 \%$ TEA pH 7.0 (60:40, v/v); 2) column: Hypersil BDS C18 (250 mm $\times 4.6 \mathrm{~mm}), 5 \mu \mathrm{m}$; 3) flow rate: $1.0 \mathrm{~mL} / \mathrm{min}$; 4) injection volume: $20 \mu \mathrm{L} ; 5)$ temperature: $25^{\circ} \mathrm{C}$; 6) run time: $25 \mathrm{~min}$; 7) detection wavelength: $275 \mathrm{~nm}$; 8) internal standard: venlafaxine.

\section{Scanning electron microscopy (SEM)}

The morphology of unprocessed/raw AC was evaluated using SEM (Quanta 400 SEM; FEI Company, Cambridge, UK). AC images were taken at different magnification power. ${ }^{21}$

\section{Transmission electron microscopy (TEM)}

TEM (Model: TEM-1200, Tokyo, Japan) was used for evaluating AC-N. AC nanosuspensions were put onto a mesh 
(200) copper grid coated with formvar/carbon, accompanied by drying the sample at room temperature.

\section{Powder X-ray diffraction (P-XRD)}

For crystallinity of AC, samples were evaluated using X-ray powder diffraction (PANalytical, X'pert Powder). The detector was scanned over $2 \theta$ angles at a step size of $0.01^{\circ}$ and well time of $10 \mathrm{~s}$ per step.

\section{Differential scanning calorimetry (DSC)}

The melting point and heat of fusion of unprocessed/raw and processed AC was determined by using DSC calorimeter (TA-60, Shimadzu, Japan). In aluminum pans, samples were heated, under nitrogen flow rate $(50 \mathrm{~mL} / \mathrm{min})$, keeping the rate of scanning $10^{\circ} \mathrm{C} / \mathrm{min}$ from $40^{\circ} \mathrm{C}$ to $200^{\circ} \mathrm{C}$.

\section{Saturation solubility}

Nanocrystals were isolated from AC nanosuspension using reported method by Shah et al, Gao et al and Thakkar et al. ${ }^{21-23}$ AC nanosuspension $(1.5 \mathrm{~mL})$ was filled into centrifugation tube and stored for a period of 24 hours, followed by centrifugation at $14,800 \mathrm{rpm}$ for 1 hour using a centrifuge. Then filtered through a filter $(0.02 \mu \mathrm{m})$, the supernatant layer was separated from dissolved drug and samples were analyzed using HPLC. Similarly, the solubility of unprocessed AC both in pure water as well as stabilizer solution was also evaluated to find out the effect of nanocrystals on saturation solubility of $\mathrm{AC}$. An adequate amount of $\mathrm{AC}$ both in pure water and stabilizer solution were placed in vials, sonicated for a time of 2 hours and the same procedure was used as mentioned earlier for AC-N. The samples were analyzed in triplicate.

\section{Stability studies}

This study was aimed to monitor the particles' growth resulted from aggregation and Ostwald ripening. The physical stability was performed for $\mathrm{AC}$ nanosuspension by subjecting $\mathrm{AC}-\mathrm{N}$ to long-term stability studies 3 months ( 90 days) at $2^{\circ} \mathrm{C}-8^{\circ} \mathrm{C}$, $25^{\circ} \mathrm{C}$ and $40^{\circ} \mathrm{C}$ temperatures. Chemical stability of AC nanosuspension was evaluated by determining the active ingredient of samples stored for 7 days using reported method as detailed earlier. At different intervals, that is, 10, 15, 30, 45, 60, 75 and 90 days, the PS and polydispersity index (PDI) were recorded using DLS and Malvern Zetasizer Nano-ZS. ${ }^{21}$

\section{In vitro dissolution}

Dissolution (in vitro) studies of unprocessed AC, AC-N, its microsuspension $(6.0 \pm 2.5 \mu \mathrm{m})$ were performed by USP
(Type-II) dissolution apparatus. Microsuspension was prepared by crushing the $\mathrm{AC}$ tablets in pestle and mortar and the stabilizer solution of $0.5 \%(\mathrm{w} / \mathrm{w}) \mathrm{HPMC}$ was added, followed by sonication in the dispersion medium as used for AC-N and marketed formulation (tablets). Dissolution medium, $0.1 \mathrm{~N} \mathrm{HCl}$ containing $2 \%$ Tween 80 was used at $75 \mathrm{rpm}$ adjusting the temperature at $37^{\circ} \mathrm{C} \pm 0.5^{\circ} \mathrm{C}$. The samples $(5 \mathrm{~mL})$ were withdrawn at different time intervals $(10,20,30,40,50$ and $60 \mathrm{~min})$ and were filtered through a syringe filter $(0.02 \mu \mathrm{m})$. The same volume of medium was replaced in order to maintain the sink conditions. ${ }^{17,21}$ The content of drug (AC) in each sample was evaluated by HPLC using method detailed earlier.

\section{In vivo bioavailability studies}

The pharmacokinetic studies were performed using Swiss albino rabbits $(2.5-3.0 \mathrm{~kg})$. Rabbits were housed in cages (wire made), with free access to water and food as per approved protocols in "Materials and methods" section. Prepared nanocrystals, unprocessed AC and marketed drug were given in a dose of $10 \mathrm{mg} / \mathrm{kg}$ by oral gavage. Venous blood in heparinized tubes at predetermined intervals $(0,0.5$, $1,1.5,2,4,6,8,12$ and 24 hours) after administration were collected. Plasma was separated from blood by centrifugation at 3,000 rpm for $20 \mathrm{~min}$ and stored frozen. All the samples (plasma) were analyzed using HPLC method by Mutalik et al as mentioned earlier. ${ }^{17}$

\section{Acute toxicity studies of AC-N}

To estimate the median lethal dose $\left(\mathrm{LD}_{50}\right)$, acute toxicity studies were conducted for AC-N on male Swiss albino mice weighing $35 \pm 5 \mathrm{~g}(\mathrm{n}=8)$. As per specification of Organization for Economic Cooperation and Development (OECD, 420) guidelines, all the samples were given by oral gavage at the dose of $25-550 \mathrm{mg} / \mathrm{kg} .{ }^{24}$ After administration of AC-N at specified doses, the toxicity and number of deaths were recorded over a time of 24 hours.

\section{Antinociceptive (analgesic) activity}

The antinociceptive activity of AC-N was determined using the acetic acid-induced abdominal constriction assay. ${ }^{25} \mathrm{AC}$ $(100 \mathrm{mg} / \mathrm{kg}$ body weight) and its nanocrystals $(10,25$ and $50 \mathrm{mg} / \mathrm{kg}$ body weight) were orally administered. Diclofenac sodium ( $50 \mathrm{mg} / \mathrm{kg}$ body weight, IP) was used as positive control. After 1 hour of drugs administration, all the animals were injected with $1 \%$ acetic acid $(10 \mathrm{~mL} / \mathrm{kg}$ body weight, IP). The abdominal writhes were counted after 10 min of acetic 
acid injection and the writhing behavior was observed for the next $20 \mathrm{~min}$. The percent protection was calculated as follows:

$$
\begin{aligned}
& \text { Percent protection } \\
& =\frac{1-\text { mean writhes in treated group }}{\text { mean writhes in control group }} \times 100
\end{aligned}
$$

\section{Statistical analysis}

The analysis was done using paired $t$-tests or analysis of variance (ANOVA) followed by Tukey's post hoc and analysis independent $t$-test. A value of $P<0.05$ was considered significant. The pharmacokinetic parameters were calculated using data analysis software, ie, PK Solutions 2.0 $0^{\mathrm{TM}}$ noncompartmental pharmacokinetic.

\section{Results and discussion Optimum conditions for fabrication of AC-N}

Stable nanocrystals of AC were produced using precipitationultrasonication approach. The nanosuspension was stabilized using HPMC, PVP K30 and SLS as depicted in Table 1 and Figure 2. There was observed a marked reduction in the final PS $(112.0 \pm 2.01 \mathrm{~nm})$ of the produced nanocrystals from the initial size $20-30 \mu \mathrm{m}$ and $115-130 \mu \mathrm{m}$ as shown in Figure 3A. TEM image evidently showed uniformity in PS distribution (PSD) PS $<200 \mathrm{~nm}$ as shown in Figure 3B.

The most stable nanosuspension with minimum PS $112 \pm 2.01 \mathrm{~nm}$ and PDI $0.165 \pm 0.01$ as achieved keeping ultrasonic input at $200 \mathrm{~W}$ with $15 \mathrm{~min}$ processing time at pause of $3 \mathrm{sec}$ as shown in Figure 4A and B. However, further increase in ultrasonic input $>200$ watts and time $>15$ min resulted in an increase in PS and PDI with rapid crystal growth, this may be because of the increase in temperature due to high energy input. This increase in temperature had also been reported by Shah et al. ${ }^{26}$

Similarly, the longer processing time was not effectively helpful in reducing PS which may be because of mixing level which has already been achieved at $15 \mathrm{~min} .{ }^{27}$ The ultrasonic input addition was found to be a kind annealing step for stable nanosuspension by lowering its energy. The lowering of energy can be achieved by converting from amorphous to a crystalline state by reordering the growth inhibitors (polymers/surfactant) on the surface of the crystal, which in turn will reduce the surface free energy. ${ }^{28}$ This energy is also reported to show an erosion effect on large crystals, cause the disruption of crystal agglomerates and enhanced adsorption rate of stabilizer on the crystal surface. ${ }^{8}$ The literature reported that working principle may be due to the creation of cavitation (bubbles), followed by collapse which releases shock waves along with pressure and temperature variations (changes) for nucleation. Faster and more uniform nucleation through the sonicated volume can be achieved by using Ultrasonic energy (waves). Reduction of agglomeration is resulted by reducing contact between particles, controlling the number of nuclei, leading to smaller and more uniformsized particles. ${ }^{13}$ All the particles shown in TEM image demonstrate a well-defined morphology associated with a crystalline material. We have also investigated that further increasing time had no marked effect on reduction of PS but instead of decreasing there was observed instability in PS and its distribution. This may be due to the generation of

Table I PS, PDI of aceclofenac using different concentration of polymers $\left(4^{\circ} \mathrm{C}\right)$ by simple precipitation and precipitation-

\begin{tabular}{|c|c|c|c|c|c|c|c|c|c|c|c|}
\hline \multirow[t]{2}{*}{ Method } & \multirow[b]{2}{*}{ 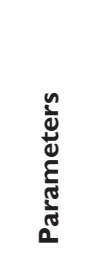 } & \multicolumn{10}{|c|}{ Formulation code (polymer/s concentration used) } \\
\hline & & 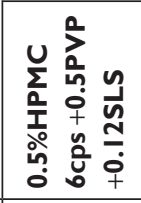 & 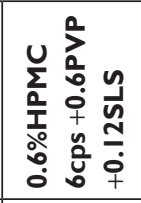 & 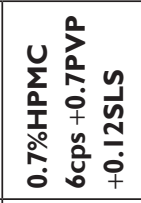 & 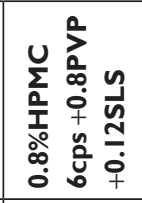 & 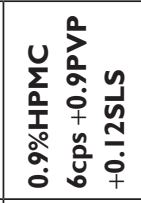 & 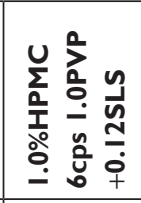 & 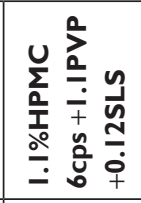 & 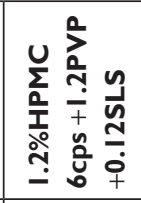 & 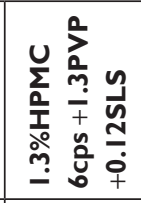 & 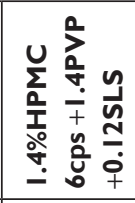 \\
\hline \multirow{2}{*}{ 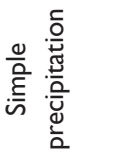 } & $\mathrm{PS}(\mathrm{nm})$ & $930.4 \pm 2.58$ & $898.2 \pm 3.85$ & $868.8 \pm 2.62$ & $795.6 \pm 3.22$ & $742.5 \pm 3.55$ & $614.3 \pm 3.34$ & $698.4 \pm 3.12$ & $735.4 \pm 3.28$ & $770.4 \pm 3.55$ & $820.4 \pm 3.15$ \\
\hline & PDI & $0.96 \pm 0.02$ & $0.89 \pm 0.01$ & $0.82 \pm 0.02$ & $0.76 \pm 0.01$ & $0.69 \pm 0.02$ & $0.57 \pm 0.02$ & $0.68 \pm 0.02$ & $0.73 \pm 0.02$ & $0.8 \mathrm{I} \pm 0.02$ & $0.87 \pm 0.02$ \\
\hline \multirow{2}{*}{ 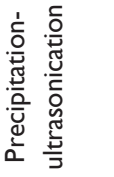 } & PS $(\mathrm{nm})$ & $710.4 \pm 3.32$ & $682.5 \pm 2.85$ & $658.3 \pm 2.34$ & $617.4 \pm 3.68$ & $492.6 \pm 3.32$ & $\mathrm{II} 2.5 \pm 2.0 \mathrm{I}$ & $324.3 \pm 2.85$ & $405.9 \pm 3.28$ & $448.9 \pm 2.68$ & $478.9 \pm 3.08$ \\
\hline & PDI & $0.84 \pm 0.0 \mathrm{I}$ & $0.76 \pm 0.02$ & $0.7 I \pm 0.01$ & $0.68 \pm 0.02$ & $0.59 \pm 0.01$ & $0.16 \pm 0.01$ & $0.38 \pm 0.02$ & $0.45 \pm 0.01$ & $0.50 \pm 0.01$ & $0.53 \pm 0.01$ \\
\hline
\end{tabular}
ultrasonication

Note: All the values are expressed as mean \pm SEM.

Abbreviations: PS, particle size; PDI, polydispersity index; HPMC 6cps, hydroxypropyl methylcellulose; PVP, polyvinylpyrrolidone; SLS, sodium lauryl sulfate. 


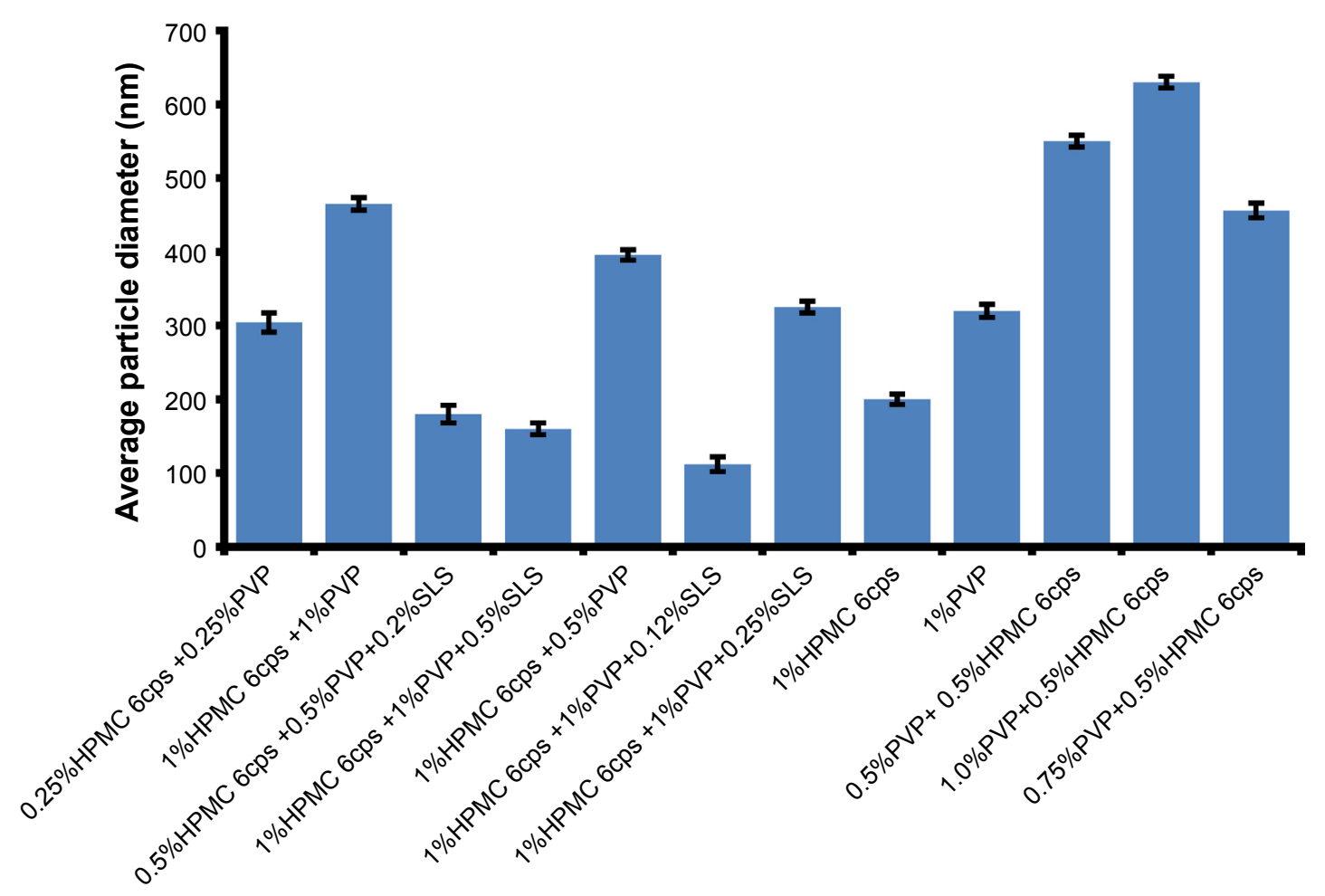

Figure 2 Effects of polymers' concentration on particle size.

Abbreviations: HPMC 6cps, hydroxypropyl methylcellulose; PVP, polyvinylpyrrolidone; SLS, sodium lauryl sulfate.

heat which is responsible for increasing the kinetic energy and saturation solubility. This effect has also reported by Shah et al. ${ }^{21}$

\section{DSC and P-XRD studies}

The results obtained from DSC thermograms are shown in Figure 5. Unprocessed AC exhibited an endotherm at $154.49^{\circ} \mathrm{C}$ conforming to its melting point. ${ }^{17}$ Optimized formulation showed a slight shift of melting point to $153.67^{\circ} \mathrm{C}$. These variances can be owing to PS difference between samples. The DSC thermogram is influenced by the packing density and PS. The existence of traces or impurities of the polymers/ stabilizers remaining on the surface of the drug particles may cause the broadening of the DSC peaks..$^{25,26,29,30}$ No new peak appears in DSC thermograms showing a lack of any chemical reaction or evidence of a new product.
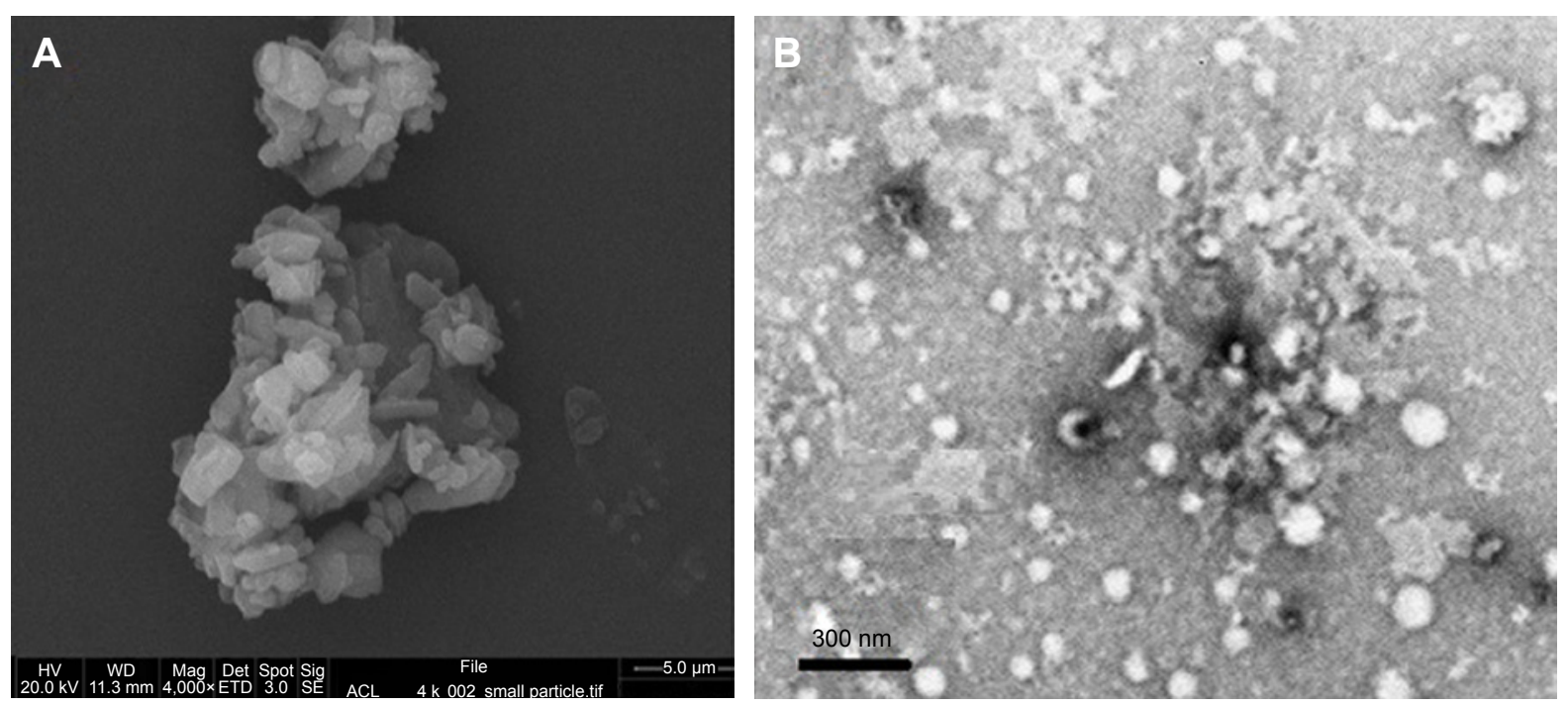

Figure 3 Scanning electron micrographs of unprocessed aceclofenac (A) and transmission electron micrographs of aceclofenac nanocrystals (B). 


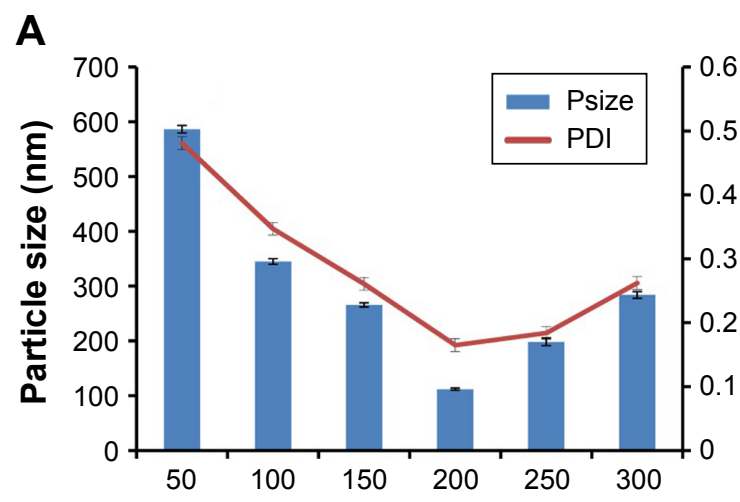

Ultrasonication power input (W)
B

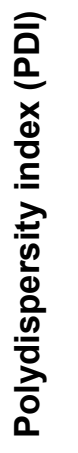

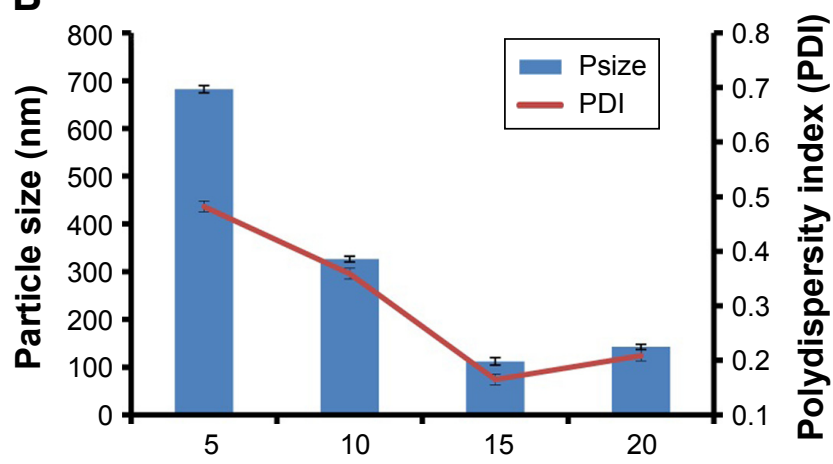

Time length (min) for ultrasonication power input

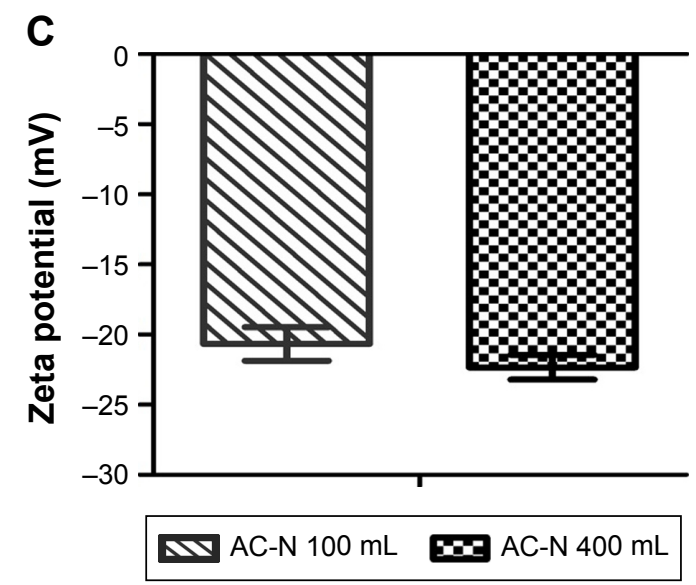

Figure 4 Effects of ultrasonication power input (A) and length of time (B) on particle size of AC-N. (C) Zeta potential values of AC-N. Abbreviation: AC-N, aceclofenac nanocrystals.

Similarly, the P-XRD results showed that the processed AC were crystalline in nature (Figure 6). However, the peak intensities of nanocrystals were relatively low compared to its unprocessed API. This effect is due to nanonization.

Furthermore, smaller PS and existence of traces amorphous polymers (as stabilizers) may cause the reduction in peaks of AC-N as shown in Figure 6. ${ }^{20,31,32}$ In addition, the $\mathrm{X}$-ray diffractogram of the physical mixture (PM) showed

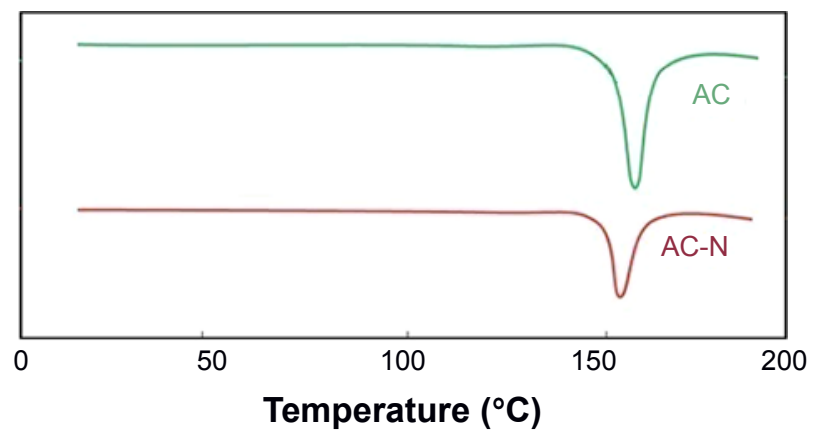

Figure 5 Differential scanning calorimetric thermogram of unprocessed aceclofenac. Abbreviations: AC, aceclofenac; $\mathrm{AC}-\mathrm{N}$, aceclofenac nanocrystals. dominant peaks for AC particles (Figure 6), while peaks for small quantity of the used polymers which were amorphous in nature did not appear.

\section{Saturation solubility}

The solubility of unprocessed AC and prepared AC-N both in pure water as well as in stabilizer solution are shown in Figure 7. The solubility of AC-N, unprocessed AC and

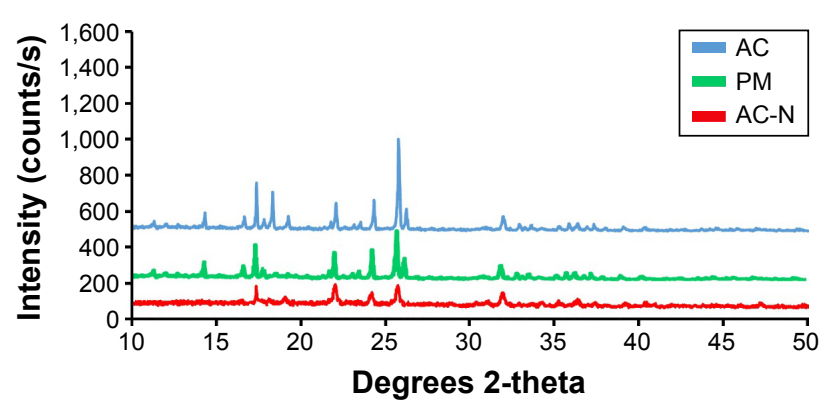

Figure 6 Powder X-ray diffraction patterns of unprocessed AC, PM and AC-N. Abbreviations: AC, aceclofenac; AC-N, aceclofenac nanocrystals; PM, physical mixture. 


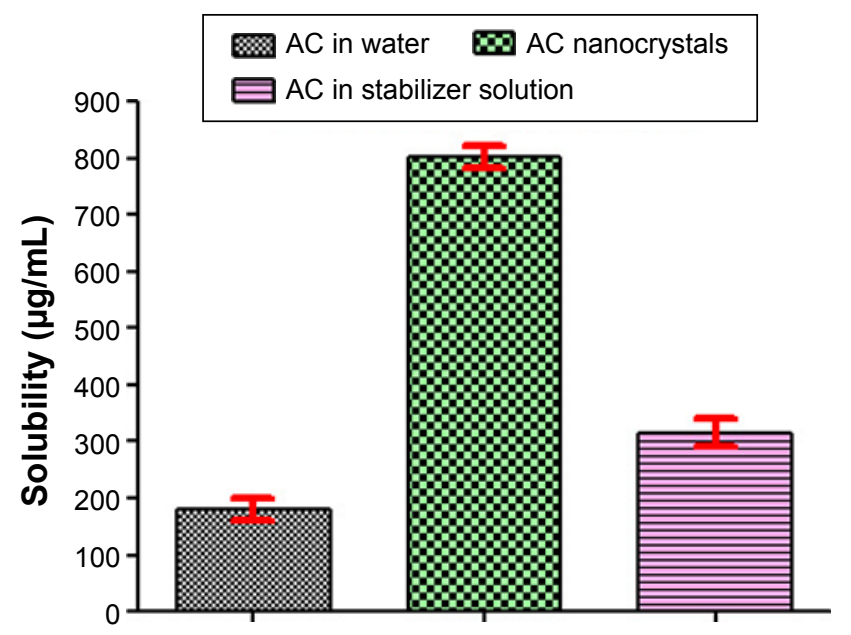

Figure 7 Solubility studies of AC nanocrystals, unprocessed $A C$ in pure water and stabilizer solution.

Abbreviation: AC, aceclofenac.

pure drug $(\mathrm{AC})$ in stabilizer solution were found to be $801.56 \pm 4.88,180.37 \pm 5.94$ and $315.99 \pm 3.64 \mu \mathrm{g} / \mathrm{mL}$, respectively. AC has poor solubility in water and reduction in PS could enhance its solubility significantly in distilled water $(P<0.05)$. AC-N showed $\sim 4.50$-fold enhanced saturation solubility as compared to AC (unprocessed), while a 2.60fold increase was found on comparing to $\mathrm{AC}$ in stabilizer solution.

\section{Stability studies}

Physical stability of AC-N was conducted at different temperatures. It is showed that $\mathrm{AC}-\mathrm{N}$ stored at $2{ }^{\circ} \mathrm{C}-8^{\circ} \mathrm{C}$ and $25^{\circ} \mathrm{C}$ (Figure 8A and $\mathrm{B}$ ) exhibited maximum stability with preserved their PDI with no significant changes in the key characteristics of nanosuspension, compared to samples kept at temperature $40^{\circ} \mathrm{C}$ (Figure 8C).

Temperature has been reported a major impact on the physical stability of the produced nanosuspension. At elevated temperatures, the interparticle interaction increased due to increase in kinetic energy (KE) of the suspended particles. The instability in nanosuspension is due to the existence of strong "van der Waals forces" which act between the nanoparticles causing an increased cluster. ${ }^{33}$ Freitas and Müller recommended that nanosuspension should be kept at $2{ }^{\circ} \mathrm{C}-8^{\circ} \mathrm{C}$ temperature, in order to achieve maximum stability. ${ }^{34}$

In addition, the zeta potential measurements for the produced nanocrystals were carried out, which resulted
A

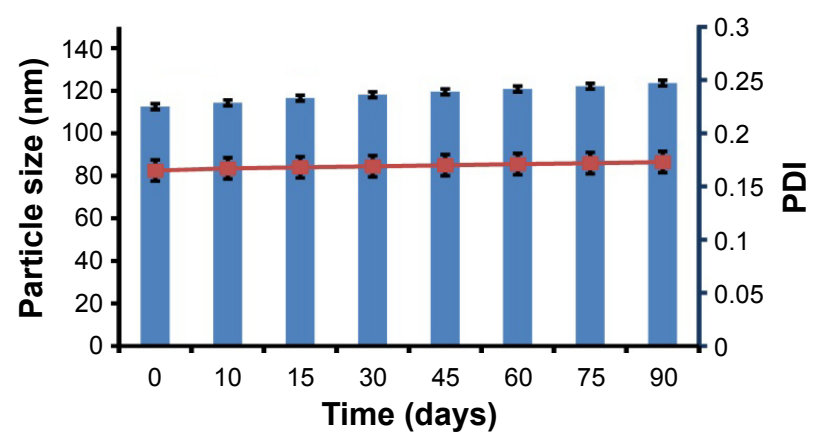

B

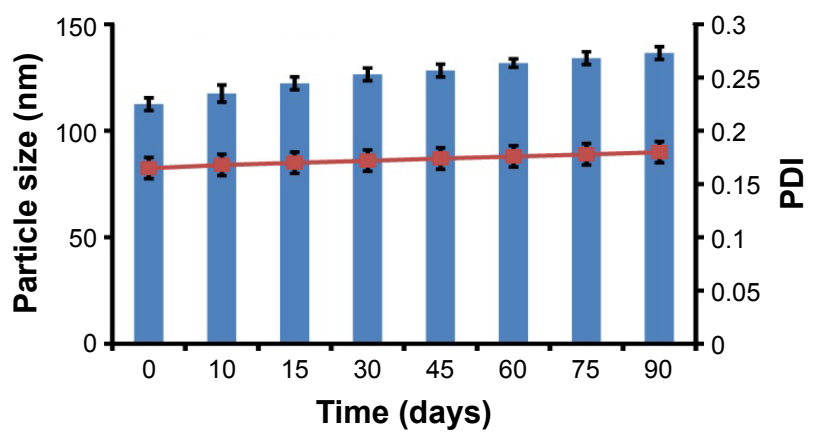

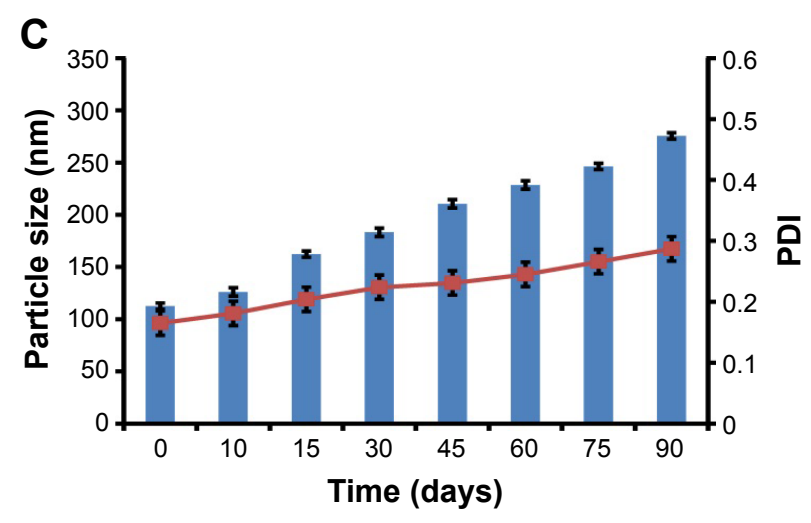

PS - PDI

Figure 8 Physical stability of AC nanocrystals in terms of PS and PDI at various time points on storage at (A) $2^{\circ} \mathrm{C}-8^{\circ} \mathrm{C},(\mathbf{B}) 25^{\circ} \mathrm{C}$ and $(\mathrm{C}) 40^{\circ} \mathrm{C}$. Abbreviations: AC, aceclofenac; PDI, polydispersity index; PS, particle size. 
Table 2 Chemical stability of aceclofenac nanosuspensions for 7 days

\begin{tabular}{|c|c|c|c|c|c|c|c|c|}
\hline \multirow[t]{2}{*}{ Stability studies } & \multicolumn{8}{|c|}{ Chemical stability studies of aceclofenac nanocrystals } \\
\hline & Day 0 & Day I & Day 2 & Day 3 & Day 4 & Day 5 & Day 6 & Day 7 \\
\hline Chemical stability & $99.45 \pm 1.45$ & $99.30 \pm 1.64$ & $99.19 \pm 3.22$ & $99.11 \pm 1.25$ & $99.05 \pm 1.56$ & $98.97 \pm 0.52$ & $98.92 \pm 2.45$ & $98.87 \pm 0.48$ \\
\hline
\end{tabular}

Note: Values are expressed as \% active contents \pm SD.

in $-20.99 \mathrm{mV}$ (for $100 \mathrm{~mL}$ batch size) and $22.33 \mathrm{mV}$ (for $400 \mathrm{~mL}$ batch size) as shown in Figure 4C. The literature has reported $\pm 30 \mathrm{mV}$ value for electrostatic stabilized system (nanosuspension) and $\pm 20 \mathrm{mV}$ for steric stabilized nanosuspension. ${ }^{31,32,35,36}$ In addition, the percent recovery of active contents of AC-N was maximum, that is, $98.05 \% \pm 2.50 \%$, which showed both the efficiency of the technology and stability of drug using the combinative approach as well as shown in Table 2.

\section{In vitro dissolution studies}

The in vitro dissolution studies of the unprocessed drug, AC-N and marketed formulation (tablets) are depicted in Figure 9. The results showed a significant enhancement in the dissolution rate of $\mathrm{AC}-\mathrm{N}$ when compared with marketed product and unprocessed AC. The data showed that $>88 \%$ of AC-N were dissolved in first 10 min compared to unprocessed AC (8.38\%), microsuspension (66.65\%) and the marketed formulation $(17.65 \%)$. Enhanced dissolution rate $\sim 10.5$-, 1.4- and 5.07-fold were observed for fabricating AC-N compared to unprocessed $\mathrm{AC}$, microsuspension and marketed formulation. When the PS is reduced to the nanometer (nm) range, the saturation solubility of a drug will be increased as previously reported Xia et al, who described the relationship between the saturation solubility of the drug and the PS..$^{8,37}$

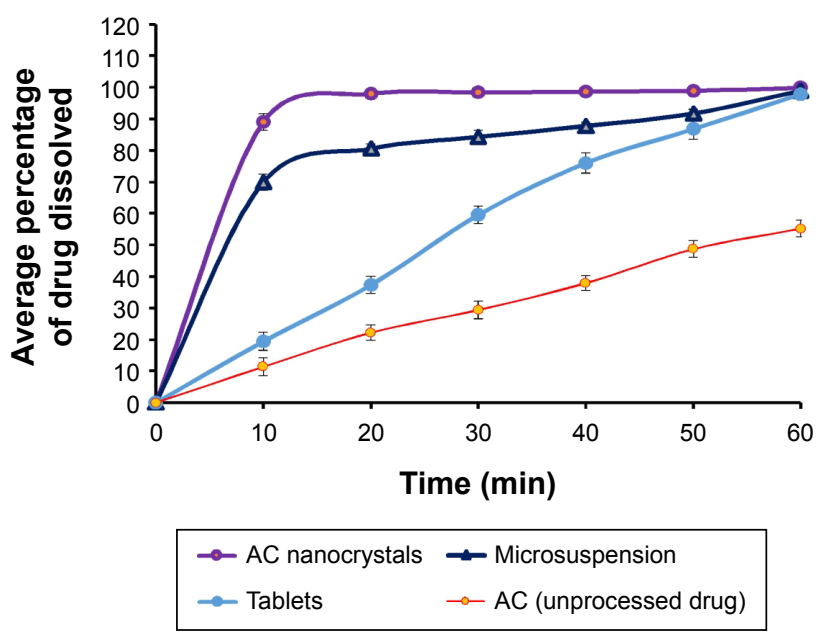

Figure 9 Comparative dissolution profile of $A C-N$, microsuspension, marketed formulation and unprocessed AC.

Abbreviations: AC, aceclofenac; AC-N, aceclofenac nanocrystals.
The literature also suggested that particles in nano range possess larger surface curvature has obviously higher vapor pressure compared to the larger unprocessed particles. ${ }^{38}$

\section{Oral bioavailability studies}

The in vivo performance of AC-N showed an enhanced absorption as compared to unprocessed API and marketed product. Similarly, the $\mathrm{C}_{\max }$ and area under curve from time of administration to $24 \mathrm{~h}\left(\mathrm{AUC}_{0 \rightarrow 24 \mathrm{~h}}\right)$ of AC-N were 4.98-, 2.80- and 3.88-, 2.10-fold greater than that of pure drug and marketed formulation, respectively, as shown in Figure 10 and Table 3.

The enhanced bioavailability of AC after oral intake could be due to faster absorption of the AC-N. This resulted because of the significant improvement in the saturation solubility due to its vast surface area, the reduced thickness of the diffusion layer and faster adhesion to the cell membrane. ${ }^{39}$

\section{Antinociceptive activity}

Administration of acetic acid was associated with significant induction of abdominal constrictions (writhes), which is an indication of nociceptive behavior. Treatment with AC $(100 \mathrm{mg} / \mathrm{kg}$ body weight) produced significant protection $(P<0.01)$ against acetic acid induced writhes. Similar protection was also afforded by the AC-N; however, the beneficial effect was observed at much lower doses of $10 \mathrm{mg} / \mathrm{kg}$ body weight $(P<0.05), 25 \mathrm{mg} / \mathrm{kg}$ body weight $(P<0.05)$ and

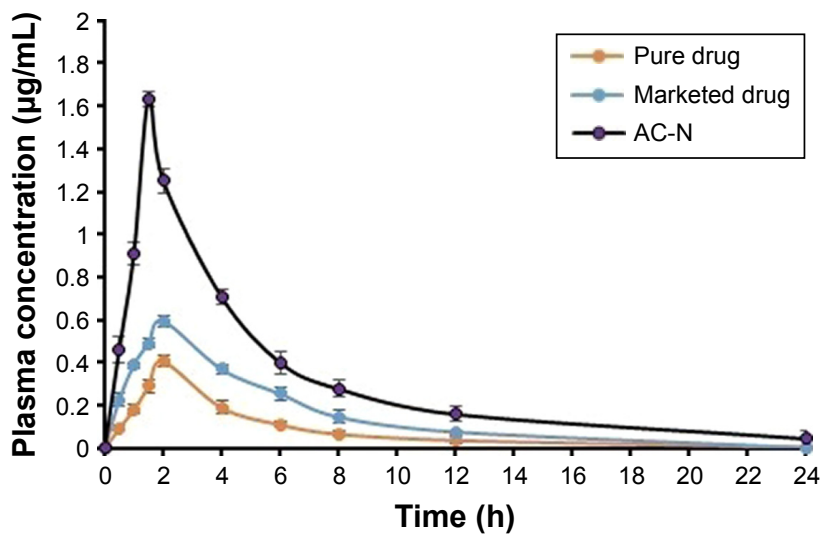

Figure 10 Average plasma drug concentration versus time profiles after oral administration of $A C-N$, marketed formulation and unprocessed $A C$. Abbreviations: AC, aceclofenac; AC-N, aceclofenac nanocrystals. 
Table 3 Pharmacokinetic parameters from the plasma concentration-time curves

\begin{tabular}{llll}
\hline Parameters & Pure drug & AC-N & Marketed \\
\hline $\mathrm{C}_{\text {max }}(\mu \mathrm{g} / \mathrm{mL})$ & $0.409 \pm 0.02$ & $1.631 \pm 0.03$ & $0.59 \pm 0.02$ \\
$\mathrm{~T}_{\text {max }}(\mathrm{h})$ & $2.0 \pm 0.00$ & $1.0 \pm 0.00$ & $2.0 \pm 0.00$ \\
$\mathrm{AUC}_{0 \rightarrow 24 \mathrm{~h}}(\mu \mathrm{g}-\mathrm{h} / \mathrm{mL})$ & $1.922 \pm 0.15$ & $7.463 \pm 0.17$ & $3.621 \pm 0.18$
\end{tabular}

Note: All values are expressed as mean $\pm S D, n=4$.

Abbreviations: $A C-N$, aceclofenac nanocrystals; $A_{U} C_{0 \rightarrow 24}$, area under curve from time of administration to $24 \mathrm{~h} ; \mathrm{C}_{\max }$, maximum plasma concentration; $\mathrm{T}_{\max }$, time for maximum plasma concentration.

$50 \mathrm{mg} / \mathrm{kg}(P<0.01)$. A robust antinociceptive effect was provided by the positive control, diclofenac sodium at the dose of $50 \mathrm{mg} / \mathrm{kg}$ body weight $(P<0.001)$ as shown in Table 4 .

\section{Acute toxicity studies of AC-N}

The $\mathrm{LD}_{50}$ (median lethal dose) studies of unprocessed $\mathrm{AC}$, marketed drug and AC-N were performed at the dose level of 25 to $550 \mathrm{mg} / \mathrm{kg}$ using Swiss Albino mice (Table 5).

At $400 \mathrm{mg} / \mathrm{kg}$, all the experimental animals were dead using unprocessed AC, marketed and nanocrystals. However, AC-N group at $250 \mathrm{mg} / \mathrm{kg}$ dose, three animals were dead which is observed in AC, marketed at a dose of $350 \mathrm{mg} / \mathrm{kg}$. Hence, the $\mathrm{LD}_{50}$ of $\mathrm{AC}$ (pure $\mathrm{AC}$ ) and marketed drug was fixed at $350 \mathrm{mg} / \mathrm{kg}$. While the $\mathrm{LD}_{50}$ for $\mathrm{AC}-\mathrm{N}$ was fixed at $250 \mathrm{mg} / \mathrm{kg}$. The low $\mathrm{LD}_{50}(250 \mathrm{mg} / \mathrm{kg})$ of AC-N compared to unprocessed $\mathrm{AC}$ and marketed formulation could be due to its enhanced saturation solubility and fast dissolution rate. ${ }^{21}$

\section{Conclusion}

Precipitation-ultrasonication approach was effectively used to fabricate stable AC-N (PS and PDI). At optimal conditions like concentration of stabilizers (PVP K30 1\% w/w, HPMC $1 \% \mathrm{w} / \mathrm{w}$ and SLS $0.12 \% \mathrm{w} / \mathrm{w}$ ), ultrasonic input 200 watts and processing time of $15 \mathrm{~min}$ at pause of $3 \mathrm{~s}$, the batch size of $400 \mathrm{~mL}$ can be successfully scaled up which is the main issue associated with this technology. AC-N showed $\sim 4.5$-fold enhanced saturation solubility as compared to AC (unprocessed), while a 2.6-fold increase was found on comparing to $\mathrm{AC}$ in stabilizer solution.

Table 4 Antinociceptive effect of aceclofenac nanoparticles in the mouse abdominal constriction assay

\begin{tabular}{lll}
\hline Treatment & Dose & Protection (\%) \\
\hline Vehicle & $10 \mathrm{~mL} / \mathrm{kg}$ & $10.82 \pm 4.34$ \\
Aceclofenac & $100 \mathrm{mg} / \mathrm{kg}$ & $51.18 \pm 16.9 I^{* *}$ \\
Diclofenac sodium & $50 \mathrm{mg} / \mathrm{kg}$ & $60.61 \pm 15.04^{* * *}$ \\
Aceclofenac nanocrystals & $10 \mathrm{mg} / \mathrm{kg}$ & $41.61 \pm 20.61^{*}$ \\
& $25 \mathrm{mg} / \mathrm{kg}$ & $40.37 \pm 20.77^{*}$ \\
& $50 \mathrm{mg} / \mathrm{kg}$ & $51.82 \pm 20.88^{* *}$ \\
\hline
\end{tabular}

Notes: Values are expressed as mean protection (\%) \pm SD. $* P<0.05$, $* * P<0.01$, $* * * P<0.001$ as compared to vehicle-treated group. $\mathrm{n}=6$ mice per group.
Table $5 \mathrm{LD}_{50}$ values of AC, AC-N and marketed formulation

\begin{tabular}{llllllll}
\hline Group & \multicolumn{6}{c}{ Results of acute toxicity studies in mice ( $\mathbf{m g} / \mathbf{k g})$} \\
\cline { 2 - 8 } & $\mathbf{2 5}$ & $\mathbf{5 0}$ & $\mathbf{1 0 0}$ & $\mathbf{1 5 0}$ & $\mathbf{2 5 0}$ & $\mathbf{3 5 0}$ & $\mathbf{5 5 0}$ \\
\hline AC & $5 / 5$ & $5 / 5$ & $5 / 5$ & $5 / 5$ & $5 / 5$ & $3 / 5$ & $0 / 5$ \\
M & $5 / 5$ & $5 / 5$ & $5 / 5$ & $5 / 5$ & $5 / 5$ & $3 / 5$ & $0 / 5$ \\
AC-N & $5 / 5$ & $5 / 5$ & $5 / 5$ & $2 / 5$ & $3 / 5$ & $0 / 5$ & $0 / 5$
\end{tabular}

Abbreviations: AC, unprocessed aceclofenac; AC-N, aceclofenac nanocrystals; M, marketed formulation.

Enhanced dissolution rate $~ 10.5-, 1.4$ - and 5.07-fold were observed for fabricating AC-N compared to unprocessed $\mathrm{AC}$, microsuspension and marketed formulation. The oral bioavailability of AC in rabbits was $\sim 4$-fold increased than that of pure drug and increased 2.1-fold when compared with the marketed formulation. The antinociceptive activity results proved the fast and potent antinociceptive effect of AC-N than the unprocessed AC.

These data obviously prove that the fabricated AC-N using precipitation-ultrasonication approach were in size range which ultimately leads to improving in vivo performance, compared to unprocessed $\mathrm{AC}$ and marketed $\mathrm{AC}$ formulation in comparatively low dose. The rapid in vitro dissolution rate provided benefits in in vivo drug absorption and resulting in improved in vivo antinociceptive activity. The dissolution rate, as well as the oral bioavailability of $\mathrm{AC}$, is enhanced markedly by using this technology for rapid and efficient PS reduction to an appropriate level. These results suggest that the $\mathrm{AC}$ in the form of nanocrystals would be in favor to improve therapeutic performance in humans. This study could be used as a platform for clinical evaluation of the nanocrystal system in future after completion of experimental works.

\section{Acknowledgments}

The authors gratefully acknowledge the Department of Pharmacy, University of Malakand, Chakdara, Khyber Pakhtunkhwa, Pakistan; Department of Pharmacy, Faculty of Life Sciences, Sarhad University of Science and Information Technology Peshawar, Khyber Pakhtunkhwa, Pakistan for support and providing resources to execute this research work. The authors are also thankful to the Deanship of Scientific Research, King Saud University, Riyadh, Saudi Arabia, for funding the project through the research group Project no RGP-262.

\section{Disclosure}

The authors report no conflicts of interest in this work.

\section{References}

1. Sahu BP, Das MK. Nanosuspension for enhancement of oral bioavailability of felodipine. Appl Nanosci. 2014;4(2):189-197. 
2. Dizaj SM, Vazifehasl Z, Salatin S, Adibkia K, Javadzadeh Y. Nanosizing of drugs: effect on dissolution rate. Res Pharm Sci. 2015;10(2):95-108.

3. Sabzevari A, Adibkia K, Hashemi H, et al. Polymeric triamcinolone acetonide nanoparticles as a new alternative in the treatment of uveitis: in vitro and in vivo studies. Eur J Pharm Biopharm. 2013;84(1):63-71.

4. Rabinow BE. Nanosuspensions in drug delivery. Nat Rev Drug Discov. 2004;3(9):785-796.

5. Kesisoglou F, Panmai S, Wu Y. Nanosizing-oral formulation development and biopharmaceutical evaluation. Adv Drug Deliv Rev. 2007; 59(7):631-644.

6. Sinha B, Müller RH, Möschwitzer JP. Bottom-up approaches for preparing drug nanocrystals: formulations and factors affecting particle size. Int J Pharm. 2013;453(1):126-141.

7. Salazar J, Müller RH, Möschwitzer JP. Combinative particle size reduction technologies for the production of drug nanocrystals. J Pharm (Cairo). 2014;2014:265754.

8. Xia D, Quan P, Piao H, et al. Preparation of stable nitrendipine nanosuspensions using the precipitation-ultrasonication method for enhancement of dissolution and oral bioavailability. Eur J Pharm Sci. 2010;40(4):325-334.

9. Reverchon E. Supercritical antisolvent precipitation of micro-and nanoparticles. J Supercritical Fluids. 1999;15(1):1-21.

10. Pathak P, Meziani MJ, Desai T, Sun YP. Formation and stabilization of ibuprofen nanoparticles in supercritical fluid processing. J Supercritical Fluids. 2006;37(3):279-286.

11. Li H, Wang J, Bao Y, Guo Z, Zhang M. Rapid sonocrystallization in the salting-out process. J Crystal Growth. 2003;247(1):192-198.

12. Louhi-Kultanen M, Karjalainen M, Rantanen J, Huhtanen M, Kallas J. Crystallization of glycine with ultrasound. Int J Pharm. 2006;320(1): 23-29.

13. De Castro ML, Priego-Capote F. Ultrasound-assisted crystallization (sonocrystallization). Ultrason Sonochem. 2007;14(6):717-724.

14. Merisko-Liversidge EM, Liversidge GG. Drug nanoparticles: formulating poorly water-soluble compounds. Toxicol Pathol. 2008;36(1):43-48.

15. Douroumis D, Fahr A. Nano-and micro-particulate formulations of poorly water-soluble drugs by using a novel optimized technique. Eur J Pharm Biopharm. 2006;63(2):173-175.

16. Lindfors L, Forssén S, Westergren J, Olsson U. Nucleation and crystal growth in supersaturated solutions of a model drug. J Colloid Interface Sci. 2008;325(2):404-413.

17. Mutalik S, Anju P, Manoj K, Usha AN. Enhancement of dissolution rate and bioavailability of aceclofenac: a chitosan-based solvent change approach. Int J Pharm. 2008;350(1):279-290.

18. Soni T, Nagda C, Gandhi T, Chotai N. Development of discriminating method for dissolution of aceclofenac marketed formulations. Dissolution Technol. 2008;15(2):31.

19. Tran TT, Tran PH, Nguyen MN, et al. Amorphous isradipine nanosuspension by the sonoprecipitation method. Int J Pharm. 2014;474(1):146-150.

20. Khan S, Matas Md, Zhang J, Anwar J. Nanocrystal preparation: lowenergy precipitation method revisited. Crystal Growth Des. 2013; 13(7):2766-2777.

21. Shah SMH, Ullah F, Khan S, et al. Smart nanocrystals of artemether: fabrication, characterization, and comparative in vitro and in vivo antimalarial evaluation. Drug Des Devel Ther. 2016;10:3837-3850.
22. Gao L, Zhang D, Chen M. Drug nanocrystals for the formulation of poorly soluble drugs and its application as a potential drug delivery system. J Nanoparticle Res. 2008;10(5):845-862.

23. Thakkar H, Nangesh J, Parmar M, Patel D. Formulation and characterization of lipid-based drug delivery system of raloxifene-microemulsion and self-microemulsifying drug delivery system. JPharm Bioallied Sci. 2011;3(3):442-448.

24. No OT. 423: acute oral toxicity-acute toxic class method. $O E C D$ guidelines for the Testing of Chemicals (Section 4: Health Effects). 2001:1-14

25. Collier H, Dinneen L, Johnson CA, Schneider C. The abdominal constriction response and its suppression by analgesic drugs in the mouse. Br J Pharmacol Chemother. 1968;32(2):295-310.

26. Shah S, Ullah F, Khan S, Shah S, Sadiq A. Combinative precipitation ultrasonication approach for fabrication for stable artemisinin nanosuspension. Am Eurasian J Agric Environ Sci. 2016;16(2): 390-401.

27. Lonare AA, Patel SR. Antisolvent crystallization of poorly water soluble drugs. Int J Chem Eng Appl. 2013;4(5):337.

28. Kipp JE, Wong JCT, Doty MJ, Werling J, Rebbeck CL, Brynjelsen S. Method for preparing submicron particle suspensions: Google Patents US 6884436 B2. 2005 Apr 26.

29. Bunjes H, Koch MH, Westesen K. Effect of particle size on colloidal solid triglycerides. Langmuir. 2000;16(12):5234-5241.

30. Valleri M, Mura P, Maestrelli F, Cirri M, Ballerini R. Development and evaluation of glyburide fast dissolving tablets using solid dispersion technique. Drug Dev Ind Pharm. 2004;30(5):525-534.

31. O'Mahony M, Leung AK, Ferguson S, Trout BL, Myerson AS. A process for the formation of nanocrystals of active pharmaceutical ingredients with poor aqueous solubility in a nanoporous substrate. Org Process Res Dev. 2014;19(9):1109-1118.

32. Ali HS, York P, Ali AM, Blagden N. Hydrocortisone nanosuspensions for ophthalmic delivery: a comparative study between microfluidic nanoprecipitation and wet milling. $J$ Control Release. 2011;149(2): $175-181$.

33. Wu L, Zhang J, Watanabe W. Physical and chemical stability of drug nanoparticles. Adv Drug Deliv Rev. 2011;63(6):456-469.

34. Freitas C, Müller RH. Effect of light and temperature on zeta potential and physical stability in solid lipid nanoparticle ( $\left.\mathrm{SLN}^{\mathrm{TM}}\right)$ dispersions. Inte J Pharm. 1998;168(2):221-229.

35. Jacobs C, Müller RH. Production and characterization of a budesonide nanosuspension for pulmonary administration. Pharm Res. 2002;19(2): 189-194.

36. Prabu SL, Sharavanan S, Govindaraju S, Suriyaprakash T. Formulation development of aceclofenac nanosuspension as an alternative approach for improving drug delivery of poorly soluble drugs. Int J Pharm Sci Nanotechnol. 2013;6(3):2145-2153.

37. Junyaprasert VB, Morakul B. Nanocrystals for enhancement of oral bioavailability of poorly water-soluble drugs. Asian J Pharm Sci. 2015; 10(1):13-23.

38. Junghanns J, Müller RH. Nanocrystal technology, drug delivery and clinical applications. Int J Nanomedicine. 2008;3(3):295-309.

39. Hintz RJ, Johnson KC. The effect of particle size distribution on dissolution rate and oral absorption. Int J Pharma. 1989;51(1):9-17.
Drug Design, Development and Therapy

\section{Publish your work in this journal}

Drug Design, Development and Therapy is an international, peerreviewed open-access journal that spans the spectrum of drug design and development through to clinical applications. Clinical outcomes, patient safety, and programs for the development and effective, safe, and sustained use of medicines are the features of the journal, which

\section{Dovepress}

has also been accepted for indexing on PubMed Central. The manuscript management system is completely online and includes a very quick and fair peer-review system, which is all easy to use. Visit http://www.dovepress.com/testimonials.php to read real quotes from published authors. 